\title{
Can Online College Education Make Students Smarter and More Moral? \\ A Preliminary Study of the Effects of Two Online College Course Assignments on Students' Moral Competence
}

\author{
Marina A. Klimenko \\ (University of Florida, Gainesville, mklimenko@ufl.edu) \\ Nicholas Surdel \\ (University of Florida, Gainesville, n.a.surdel@gmail.com) \\ Kathryn Muir \\ (University of Florida, Gainesville, klmuir96@gmail.com) \\ Fuaad Sofia \\ (University of Florida, Gainesville, fuaadsofia@gmail.com)
}

\section{Introduction}

Having morally competent citizens is in the interest of every society. And although moral education may no longer be the primary goal of higher education in the U.S., it nevertheless is viewed by many as one of its missions (McNeal 2009). For example, the Association of American Colleges \& Universities explicitly states, “...educators and employers agree that personal and social responsibility should be core elements of a 21st century college education if our world is to thrive." (https://www.aacu.org/ resources/civic-learning). While there is no one way to define a moral individual, moral competence: refers to the ability to solve problems and conflicts, on the basis of moral principles, through thinking and discussion (Lind 2016), seems a reasonable place to start. According to Lind's theory of moral competence (2015), education that encourages students to self-reflect and to take responsibilities for their actions can enhance moral competence. While there is some empirical evidence to support this assertion, the exact mechanisms by which students' morality is affected remains unclear. For example, is it a certain curriculum, college activities, diversity of perspective, or some combination of two or more, that foster students' moral reasoning? Furthermore, higher education is increasingly delivered online, and this raises even more questions as to whether online courses have the same effect on students' moral development. The goal of the present study was to address these questions by examining two types of online course assignments, group discussions, and critical writing with active/experiential learning in 
two psychology courses: Developmental Psychology and Research Methods Lab.

\subsection{Empirical evidence of the effect of higher education on students' moral reasoning}

There is a reasonable amount of empirical evidence suggesting that attending a college or university can enhance student's moral reasoning. For example, King and Mayhew (2002) found over 172 studies that confirmed a positive association between college attendance and students' improvement of moral reasoning. However, the studies only utilized one moral reasoning assessment, the Defining Issues Test (DIT); and the majority of them did not purposefully study the connection between higher education and student morality, but rather used college students as their convenience samples. Thus, more studies are needed to directly address the potential causality between higher education and students' improvement of moral judgement. Even less is known about the specific pedagogical strategies that work to advance students' moral reasoning. What is known will be reviewed next.

\subsubsection{Moral content}

One of the obvious ways to improve moral competence is through explicit instruction of morality and ethics. However, empirical evidence of its effectiveness is mixed. For example, Mayhew and King (2008) compared two courses with explicit moral content, Moral Choice and Contemporary Moral Problems, with three courses that included some aspect of morality such as social justice and community service. They found that improvement in moral reasoning was greater in the two explicitly taught morality courses.

In an intervention study by Cummings and her colleagues (2010), students in an Educational Psychology course who were explicitly taught theories of moral development and discussed moral dilemmas had a significantly higher increase in moral reasoning than the students in English and Philosophy courses where course content engaged in various discussions, including ones of moral nature, but were not explicitly taught about moral development. Furthermore, a study of South Korean nursing students found a significant increase in moral reasoning between freshmen and seniors, with gains positively associated with ethics course credit hours throughout their studies (Park, Kjervik, Crandell, \& Oermann 2012).

Conversely, in a sample of 821 business students across three U.S. higher education institutions, Desplaces and his colleagues (2007) found no relationship between the quantity of ethics discussions and moral competence. Although students on the whole did not show significant improvement, the sample who recalled participating in ethics discussions showed marginally significant findings (Desplaces, Melchar, Beauvais, \& Bosco 2007). 


\subsubsection{Positive peer-interaction}

Kohlberg, who is considered to be the father of Moral Psychology, proposed a theory of moral development and argued that individuals' view of morality undergoes qualitative changes at the same time as the pattern of thinking undergoes structural changes. Just like Piaget, Kohlberg argued that being confronted with opposing moral views and being able to engage in an open dialogue about different views may advance growth in moral thought. This also suggests that courses that engage students in peer-interactions in the climate of openness and acceptance can foster moral competence. Several studies have found support of this. For example, Mayhew and King (2008), found peer-interactions were one of the significant predictors of higher moral reasoning at the end of the academic term. In the intervention study by Cummings et al. (2010), courses that employed online group discussions also had students with significantly higher moral reasoning scores, however, it is not clear whether it is the interaction with the peers, the deliberation of moral dilemmas, or both types of activities that caused the increase in the students' moral reasoning. In another study by Mayhew and Engberg (2010), results showed that high levels of tension and negative affect in the classroom were associated with a decrease in students' moral reasoning. Similarly, Schillinger (2006) found that institutional pressures could either facilitate or regress students' moral competence. Specifically, an environment that promotes role taking and guided reflection significantly improved moral competence from year one; while an environment that restricts or punishes involvement and reflection decreased moral competence over time

\subsubsection{Active and experiential learning}

According to Experiential Learning Theory (ELT), learning is "the process whereby knowledge is created through the transformation of experience. Knowledge results from the combination of grasping and transforming experience" (Kolb 1984, p. 41). In the similar vein, Kohlberg (1971) and more recently, Boss (1994), have argued that experiencing real life moral dilemmas and actively solving real life moral problems will foster moral reasoning. This idea has received some empirical support. For example, Boss (1994) compared moral reasoning scores of students in two different undergraduate ethics courses. Students in both classes learned the topic of moral development and engaged in moral dilemmas as part of the course curriculum. Additionally, students in the experimental group had to complete 20 hours of community service and to keep a diary reflecting on their service. At the end of the semester, students in the experimental class demonstrated a greater increase in moral reasoning skills than the students in the class with no community service.

Similarly, St. Peters and Short (2018) demonstrated the positive effect of experiential learning in a study of ten occupational therapy students who participated in a cross- 
cultural service learning experience in Guatemala. Students assisted a lead therapist in patient assessment, as well as provided patient assessments and consultations. Students faced a myriad of cultural and professional challenges, such as communication barriers, local people's misunderstanding of the Western idea of patient's independence or the concept of rehabilitation. Similar to the students' in Boss (1994), students also kept a diary, documenting and reflecting upon their experiences. Although the sample of 10 students was rather small, the evidence of inner-growth could be inferred. Specifically, there was a significant increase in the students' measured character traits, including, curiosity, gratitude, love of learning, openness to evidence, perspective taking, propriety, self-control, social perceptiveness, spirituality, and zest. It may be that one of the ways by which students in both studies have increased their moral reasoning is by learning to see problems from multiple perspectives and appreciate the complexity of real-life dilemmas. The opposite may be true when openness to different viewpoints is restricted, as in some religious institutions. For example, Saeidi-Parvaneh (2011) found that religious dogmatism severely hindered moral competence in college students in the first and fourth year of study in medical, engineering sciences, and psychology.

In sum, research suggests that higher education can have a positive effect on students' moral reasoning in at least two ways: through positive peer-interactions and active (experiential) learning. However, it remains unclear if similar effect can be achieved in online education. Thus, the present study was set up to address this question.

\section{Method}

\subsection{Participants}

The present study was part of a larger research on morality from a major university in the U.S. Students enrolled in online Developmental Psychology (DEP) and Research Methods lab (RML) classes were recruited to participate in the study in exchange for extra credit. In the RML class, a total of 42 male and 118 female students agreed to participate. In the DEP, 29 male and 96 female students consented to participate.

\subsection{Variables}

Students in both courses engaged in two types of course activities: group discussions (i.e., peer-interaction) and class projects (i.e., active/experiential learning).

All students who agreed to participate in the study completed the Moral Competence Test (MCT) (Lind 2014) at the beginning and the end of the semester, assessing students' 
moral competence at both times. This instrument measures moral competence and moral orientation by presenting two moral dilemmas and asking participants to rate their level of being in agreement with several arguments for and against certain moral decisions. Higher moral competency reflects an individual's ability to adhere to and to be consistent in choosing one's high moral principles across different situations. Furthermore, the instrument produces lower scores for individuals who respond based on the seeking a specific outcome, regardless of the explanation. Thus, allowing the tool to directly target the moral arguments and reasoning.

\subsubsection{Developmental psychology class (DEP)}

As part of course requirement, students in the DEP class learned developmental theories of moral development and participated in group discussions, one of which involved reflecting upon Kohlberg's and Gilligan's theories of moral development; In addition, the students completed My Virtual Life simulation (Pearson 2018), which consists of two parts. In the first half of the simulation, the students parented a child from birth to age 18, making decisions as the child's parent. Then, when the virtual child turned 18, the students became the virtual adult and lived as one experiencing the effects of the decisions that they made as the child parent. Then, they wrote two reflective papers describing their virtual experiences and critically evaluating them. The grades for the two papers were summed to create one variable. To determine if moral content of the course had a unique role in the improvement of moral competence, the grades on the quiz testing students understanding of moral development was also included in the analysis.

\subsubsection{Research methods lab class (RML)}

The primary purpose of this course is to introduce students to basic designs of research in Psychology. In addition, students learn to develop better critical and scientific thinking. Students engaged in several group discussions; and they designed a research project, collected and analyzed data, and wrote a research paper describing their findings.

\section{Results}

\subsection{Did the students' moral competence improve at the end of the semester?}

To examine the change in the level of the students' moral competence at the end of their respective courses, two separate paired-samples t-tests were computed. In the RML class, there was a significant difference in the moral competence scores between time $1(M=17.6, S D=12.9)$ and time $2(M=20.6, S D=15.4)$, having higher level at the end of the semester; $t(128)=-2.46, p=.015$. In the DEP class, the difference in the MCT scores 
between time $1(M=15.0, S D=10.9)$ and time $2(M=17.6, S D=12.5)$ was only approaching significance, $t(492)=-1.88, p=.062$.

\subsection{What course assignments contributed to the students' higher moral competence levels?}

To examine the relative contribution of the assignments to the improvement in the moral competence scores, two separate hierarchical regression analyses were computed, one with only the developmental psychology class (see Table 1) and another with the research methods lab class (see Table 2). In both analyses, moral competence at time 1 was entered first, followed by the final grades to control for students' overall performance in the classes; finally, the respective assignments were entered in the final step.

\subsubsection{Developmental Psychology class}

In the Developmental psychology class, moral competence at time 1 was a significant contributor, $F(1,106)=11.2, p=.001$, explaining $10 \%$ of the variation in the moral competence at time 2. Final grades and moral competence at time 1 together explained $13 \%$ of the variation in the moral competence at time 2 in step 2 , and this change in $\mathrm{R}^{2}$ was significant, $F(2,105)=7.91, \mathrm{p}=.001$. Adding all assignments to the regression model explained an additional $17 \%$ of the variation in moral competence at time 2 and this change in $\mathrm{R}^{2}$ was significant, $F(5,102)=4.01, \mathrm{p}=.002$. When all independent variables were included in stage three of the regression model, only moral competence at time 1 and grades for group discussion were the significant predictors of the moral competence at time 2 (see Table 1).

\begin{tabular}{|c|c|c|c|c|}
\hline Variables & & B & SE B & $\boldsymbol{\beta}$ \\
\hline Step 1 & MCT time 1 & .36 & .11 & .31 \\
\hline \multirow[t]{2}{*}{ Step 2} & MCT time 1 & .36 & .11 & .31 \\
\hline & Final Grades & -.30 & .15 & -.19 \\
\hline \multirow[t]{5}{*}{ Step 3} & MCT time 1 & .32 & .11 & .28 \\
\hline & Final Grades & -.47 & .33 & -.29 \\
\hline & Paper & -.04 & .25 & -.03 \\
\hline & $\begin{array}{l}\text { Moral } \\
\text { Development } \\
\text { Ouiz }\end{array}$ & -.71 & 1.97 & -.04 \\
\hline & $\begin{array}{l}\text { Group } \\
\text { Discussions }\end{array}$ & 1.13 & .58 & $.23^{*}$ \\
\hline
\end{tabular}

Table 1: Summary of Hierarchical Regression Analysis for Variables Predicting Moral Competence at the End of the Semester in Developmental Psychology Class ( $N=108)$ 


\subsubsection{Research methods lab class}

Similar to the Developmental Psychology class, moral competence at time 1 was a significant contributor to the model at step $1, F(1,113)=46.2, p=.000)$, but explained a much larger proportion, $29 \%$ of the variation in the moral competence at time 2 . Final grades and the initial moral competence explained 29\% of the variation in the moral competence at time 2 but this change in $\mathrm{R}^{2}$ was not significant, $F(1,112)=.49$, $\mathrm{p}=.49$. Adding the two assignments, the research paper and the group discussions, to the regression model explained $31 \%$ of the variation in the moral competence at time 2 and this change in $\mathrm{R}^{2}$ was significant, $F(2,110)=3.13, \mathrm{p}=.047$. The examination of the coefficients' table revealed that only the research paper was a significant and a negative contributor to the moral competence test scores at the end of the semester (see Table 2).

\begin{tabular}{|l|l|l|l|l|}
\hline Variables & & $\mathbf{B}$ & SE B & $\boldsymbol{\beta}$ \\
\hline Step 1 & MCT time 1 & .64 & .09 & .54 \\
\hline Step 2 & MCT time 1 & .64 & .09 & .54 \\
\cline { 2 - 5 } & Final Grades & .08 & .11 & .06 \\
\hline Step 3 & MCT time 1 & .65 & .09 & .55 \\
\cline { 2 - 5 } & Final Grades & .75 & .31 & .53 \\
\cline { 2 - 5 } & Research Paper & -.48 & .20 & $-.51^{*}$ \\
\cline { 2 - 5 } & Group Discussions & -.22 & .84 & -.02 \\
\hline
\end{tabular}

Table 2: Summary of Hierarchical Regression Analysis for Variables Predicting Moral Competence at the End of the Semester in Research Methods lab Class (N=108)

Since the negative association between moral competence and the research papers was an unexpected and unusual finding, a follow up analysis testing for potential multicollinearity (It is known to cause the coefficients to be sensitive to changes in the model, including changes in the signs). Multicollinearity was tested with variance inflation factors test (VIF). The test revealed that both, final grades and research papers' grades, had VIFs of 7 , which is greater than the critical value of 5 , representing high correlations with the independent variable, moral competence at time 2. Typically, to fix this issue, one of the highly correlated variables must be dropped from the model. Thus, the final grades variable was dropped from the final regression model. After rerunning the model, the results showed that only the moral competence scores at time 1 was the significant predictor of the moral competence at the end of the semester $(\beta=.54, \mathrm{p}=.00)$. Thus, it was inferred that no assignments significantly contributed to the improvement in the moral competence in the RML class.

\section{Discussion}

The goal of the present study was to examine the effectiveness of two online Psychology courses in fostering moral competence, which refers to the ability to solve 
problems and conflicts on the basis of moral principles through thinking and discussion (Lind 2016). Specifically, the study has examined students' moral competence at the beginning and the end of the semester in relation to their grades on two class assignments in their respective courses. Overall, students in the RML demonstrated a significant increase in their moral competence at the end of the semester. Students in the DEP also showed an increase in their moral competence scores, but the difference was only approaching statistical significance. Taken together, these findings provide partial support to the claim that higher education is capable of fostering moral reasoning; moreover, online psychology courses, even those that do not explicitly cover moral content, such as the RML, seem to be able to have a positive effect.

The study also examined the link between students' moral competence scores and the two courses' major assignments. Specifically, in both courses two types of assignments were examined: peer-interaction in the form of online group discussions and active/ experiential learning, either in the form of participating in a research project or in two simulations. In the DEP, students participated in several group discussions, by posting their original responses to the instructor's prompts and replying to their peers' postings. The topics of the discussions varied; but one of the discussions was based on the topic of moral development, and, specifically, on the theory of Kohlberg's and Gilligan's theories of moral development. The students were asked to reflect upon both theories and to share with their group one moral dilemma that they personally had overcome. For the second assignment, students raised a virtual baby and simulated an adult life; at the end of both simulations, the students wrote two reflection papers. The analysis showed that only group discussions were significantly associated with the increase in the students' moral competence at the end of the semester. That is, students who demonstrated better engagement and earned higher grades on the group discussions had higher levels of moral competence at the end of the semester. This finding further confirms past finding that positive peer interaction, even as online group discussions, can benefit students' moral development, and thus, should be offered in online courses, whenever possible.

As for the RML course, the findings were not as predicted. Similar to the DEP course, the students engaged in several group discussions following the same rules (i.e., to write an original post and reply to one peer's post). Unlike the DEP, the course did not explicitly cover topics of morality, however, at least one topic and one group discussion touched on the issue of ethics in psychological research. Still, according to the results of the analysis, group discussions did not significantly contribute to the students' improvement in moral competence. One possible interpretation for this failure is to suggest that, perhaps, only those courses and assignments that explicitly focus around the topics of moral nature may have the positive effect of raising students' moral thought. However, this doesn't explain why the students in the RML course had a significant increase in their moral 
reasoning, and had greater levels of moral competence at the beginning and end of the semester than their counterparts' in DEP course. One possible explanation may lie in the cognitive demand and critical thinking skills necessary to make sound moral decisions. According to Kohlberg, an individual must undergo "a qualitative re-organization" of pattern of thinking about fairness and justice (Colby \& Kohlberg 1987, 5) in order to advance his/her moral reasoning. Although, the content of the RML course does not have a moral dimension in its curriculum, it teaches students how to gather and evaluate evidence based on scientific rigor and critical thinking rather than personal opinions or emotions. This might have the positive effect on students' moral reasoning. Additionally, it is possible that students with more advanced cognitive skills chose to take RML course, as it is considered one of more challenging courses in Psychological studies.

Similar to the DEP course, the performance on the research project did not seem to contribute to students' moral competence at the end of the semester in RML. One possible explanation is that active/experiential learning in both courses did not include a moral dimension in order to have an impact on students' line of moral reasoning. Alternatively, at a minimum, such assignments did not "trigger cognitive disequilibrium" (Rest 1986) or perspective-taking, which are both critical elements of active learning that are known to facilitate the development of moral reasoning (see Mayhew \& King 2008). Finally, it is possible that the grading of both assignments did not capture the efforts of the students in the area of perspective-taking and/or did not challenge cognitive equilibrium. This latter explanation needs to be seriously examined by the instructor and first author, as it may undermine classroom morale and students' perception of fairness, which in turn can have a regressive effect on students' moral competence (e.g., Schillinger 2006).

Additionally, it must be highlighted that the average scores of moral competence in both courses were very low compared to the samples in other studies using MCT instrument (e.g., Schillinger 2006). One likely explanation for this is the fact that the students in the present study were under a lot of pressure at the end of the semester, either preparing for the final exam or working on their research projects. Thus, the element of fatigue or stress influencing students' performance on the moral competence test cannot be ruled out.

A potential flaw in the design of the study is the selection bias. Specifically, it is possible that students who chose to participate in the study differed from those who opted for an alternative extra credit assignment or to not do any extra credit assignment. To check this possibility, the grades of the students who participated in the study were compared with those who did not participate. The analyses revealed no significant differences between the students in the DEP course. However, a statistical significance in the final grades was found in the RML course. Specifically, the final grades of the students who did not participate in the study were higher than those who participated. This selection bias might have contributed to the lack of some findings in the RML course. However, it is worth noting that an improvement in the moral competence was still found 
in the RML course.

The results of the study should also be treated with caution for at least one more reason. The same instructor taught both courses. While this helped to control for a potential instructor effect, it remains unclear whether the outcomes will be the same under a different instructor, especially, who is novice to moral development. For example, instructor's level of moral development has been shown to influence his/her teaching style and the overall climate in the classroom, which in turn may influence students' performance and even perception of the course material (e.g., Johnston 1989).

In conclusion, despite the aforementioned limitations, the study provides good evidence that online psychology courses can foster moral competence; specifically, that engaging students in online group discussions improves their moral reasoning skills, possibly by encouraging them to question their own views and believes and by exposing them to alternative perspectives. Furthermore, this can also suggest that other kinds of course assignments, either in written or oral form, that raise students' awareness of others' points of views and encourage re-evaluation of ones' own believes may also be beneficial in raise moral competence and should be offered in higher education.

\section{References}

Boss J. A. 1994. "The Effect of Community Service Work on the Moral Development of College Ethics Students. Journal of Moral Education 23(2):183-98. Retrieved from https://digitalcommons.unomaha.edu/slcehighere d/87.

Desplaces D. E., Melchar D. E., Beauvais L. L., \& Bosco S. M. 2007. "The Impact of Business Education on Moral Judgment Competence: An Empirical Study.” Journal of Business Ethics 74:73-87.

Colby A. \& Kohlberg L. (with A. Abrahami, J. Gibbs, A. Higgins, K. Kauffman, M. Lieberman, M. Nissan, J. Reimer, D. Schrader, J. Snarey, \& M. Tappan). 1987. The Measurement of Moral Judgment, Vols I and II. Cambridge University Press. Cummings R., Maddux C., Cladiano A., \& Richmond A. S. 2010. "Moral Reasoning of Education Students: The Effects of Direct Instruction in Moral Development Theory and Participation in Moral Dilemma Discussion." Teachers College Record 112(3).

Johnston M. 1989. “Moral Reasoning and Teachers' Understanding of Individualized Instruction." Journal of Moral Education 18:45-59.

Kolb D. A. 1984. Experiential Learning: Experience as the Source of Learning and Development. Englewood Cliffs, N.J.: Prentice-Hall, Inc.

Kohlberg L. 1971. The Philosophy of Moral Education. New York, NY: Harper \& Row. 
King P. \& Mayhew M. 2002. "Moral Judgement Development in Higher Education: Insights from the Defining Issues Test." Journal of Moral Education. doi 31.10.1080/0305724022000008106.

Lind G. (2014, March 24). Moral Competence Test (MCT), from http://www.unikonstanz.de/ag-moral/mut/mjt-engl.htm.

Lind G. 2016. How to Teach Morality. Promoting Deliberation and Discussion, Reducing Violence and Deceit. Berlin: Logos.

Lind G. \& Nowak E. 2015. "Kohlberg's Unnoticed Dilemma-The External Assessment of Internal Moral Competence?," in B. Zizek, D. Gartz, E. Nowak (Eds.), Kohlberg Revisited. Sense Publishers, Rotterdam - Taipei (139-53).

Mayhew M. J. \& King P. 2008. "How Curricular Content and Pedagogical Strategies Affect Moral Reasoning Development in College Students." Journal of Moral Education $37: 17-40$.

Mayhew M. J. \& Engberg M. E. 2010. “Diversity and Moral Reasoning: How Negative Diverse Peer Interactions Affect the Development of Moral Reasoning in Undergraduate Students." The Journal of Higher Education 81(4):459-88.

McNeel S. 1994. “College Teaching and Student Moral Development," in J. Rest \& D. Narvaez (Eds.), Moral Development in the Professions: Psychology and Applied Ethics. Hillsdale, NJ: Lawrence Erlbaum Associates (27-47).

Park M., Kjervik D., Crandell J., \& Oermann M. H. 2012. "The Relationship of Ethics Education to Moral Sensitivity and Moral Reasoning Skills of Nursing Students." Nursing Ethics 19(4):568-80. doi:10.1177/0969733011433922

Pearson 1996-2018. https://www.pearson.com/us/higher-education/program/ Pearson-Education-MY-VIRTUAL-CHILD/PGM253641.html

Rest J. R. 1986. Moral Development: Advances in Research and Theory. New York: Praeger. Saeidi-Parvaneh S. 2011. Moral, Bildung und Religion im Iran - Zur Bedeutung universitärer Bildung für die Entwicklung moralischer Urteils- und Diskursfähigkeit in einem religiös geprägten Land. [Morality, Education and Religion in Iran. On the Importance of University Education for the Development of Moral Judgment and Discourse Competence in a Religiously Shaped Country.] Doctoral dissertation, Department of Psychology, University of Konstanz. http://kops.ub.uni-konstanz. de/volltexte/2011/13107/

Schillinger M. 2006. Learning Environments and Moral Development: How University Education Fosters Moral Judgment Competence in Brazil and two German-Speaking Countries. Aachen: Shaker-Verlag.

St. Peters H. Y.Z . \& Short N. 2018. "Cross-Cultural Service Learning as Pedagogy for Character Development in Occupational Therapy Doctoral Students." The Open Journal of Occupational Therapy 4(6). Article 8. doi:10.15453/2168-6408.1493 
Marina A. Klimenko, Nicholas Surdel, Kathryn Muir, Fuaad Sofia (Gainesville)

\title{
A Preliminary Study of the Effects of Online College Course Assignments on Students' Moral Competence
}

\begin{abstract}
Higher education institutions in the United States have historically been tasked with the responsibility of scaffolding the moral development of students. Although empirical evidence suggests that attending colleges and universities can foster students' moral development and reasoning, the effect of online higher education remains mainly unknown. The current study has examined the effect of two online psychology courses, Developmental Psychology and Research Methods Lab, and their respective assignments on students' moral competence. The findings revealed that students' moral competence in both courses was improved; this improvement was partly attributed to online group discussions in the Developmental psychology course. No other assignments were found to be significant contributors of students' moral competence. Limitations and implications of the findings were discussed.
\end{abstract}

Keywords: Morality; Higher Education; Online Higher Education; Moral Competence, Moral Development.

Ethics in Progress (ISSN 2084-9257). Vol. 9 (2018). No. 2, Art. \#4, pp. 44-55.

Creative Commons BY-SA 3.0

Doi:10.14746/eip.2018.2.4 